\title{
Polypeptides as Models for Membrane-Active Proteins
}

\author{
Yukio IMANISHI \\ Department of Polymer Chemistry, Faculty of Engineering, \\ Kyoto University, Yoshida Honmachi, Sakyo-ku, Kyoto 606, Japan
}

(Received August 20, 1984)

\begin{abstract}
A cyclic oligopeptide, linear sequential polypeptides, and glycopeptides were synthesized and their activities in lipid assemblies were investigated in relation to conformational properties. First, a cyclic octapeptide, cyclo(D-Leu-L-Pro) ${ }_{4}$, transported efficiently $\mathrm{Ba}^{2+}$ across $\mathrm{CHCl}_{3}$ membrane. It transported calcium picrate across a liposomal membrane, which was evidenced by the fluorescence of chlorotetracyclin dissolved in the interior of the liposome. Secondly, sequential peptides, Boc-(Leu-Leu-D-Phe-Pro) ${ }_{n}$-OBzl ( $n=3$ and 4), and a sequential polymer, poly(Leu-Lue-D-Phe-Pro) took $3_{10}$ helix conformation in nonpolar organic solvent, and the polymer yielded an electric current under an electric field, when it was added to bilayer lipid membrane (BLM) composed of oxidized cholesterol. This result indicates the formation of pores on the BLM through which ions permeate. The pores were possibly formed by folding and intramolecular association of the sequential polymer with $3_{10}$ helix conformation in BLM. Thirdly, a linear dipeptide Boc-Asp- $\varepsilon$-Lys-OMe was prepared, in which the $\alpha$-amino group of the Lys unit was protected with pyrene butyryl group as a fluorecent probe and the $\beta$-carboxyl group of Asp unit was linked by an amide bond to $1-\beta$-amino-acetylglucosamine which interacts specifically with a lectin, wheat germ agglutinin (WGA). Liposomes containing the glycodipeptide were associated by the addition of WGA. The association did not occur by the addition of unspecific lectin, phytohemagglutinin. The fluidity of liposome decreased on adding the glycodipeptide, but was restored by the further addition of WGA. Similar phenomena were observed when $\mathrm{Ca}^{2+}$ was added to liposomes containing a dipeptide without the sugar group.
\end{abstract}

KEY WORDS cyclo(D-Leu-L-Pro) 4 / Ion Transport / Liposome / Poly(Leu-

Leu-D-Phe-Pro) / 310 Helix / Ion Channel / Bilayer Lipid Membrane /

Glycodipeptide / Wheat Germ Agglutinin / Patching /

It has been widely recognized that cell is an epitome of life. Almost all life phenomena take place in cell membrane, and proteins or glycoproteins in cell membrane play an essential role in the life phenomena. Therefore, it may be helpful to use synthetic peptides as models for membrane-active proteins in understanding the mechanism of life phenomena.

Muscle contraction, transmittance of neuro impulse, some of antibiotic actions, and generation of membrane potential take place as a result of ion permeation across cell membrane, which is mediated by ionophore. There are two types of ionophores, one of them being carrier ionophores and the other channel-forming ionophores.

Naturally occurring carrier ionophores such as valinomycin and enniatin $\mathrm{B}$ transport metal ions and ionic molecules across biomembrane. ${ }^{1}$ In my laboratory, cyclo(L-Leu-L-Pro) ${ }_{4}$ has been synthesized previously as a carrier ionophore model. ${ }^{2}$ It bound alkali and alkaline-earth metal ions ${ }^{3}$ and transported these ions efficiently across $\mathrm{CHCl}_{3}$ membrane. ${ }^{4}$ However, it did not transport metal ions across lipid membrane, which was ascribed to a slow complex formation with metal ions in the lipid membrane system. ${ }^{4}$ Cyclo(D-Leu-L-Pro) ${ }_{4}$ was expected to be an efficient ion carrier across liquid and lipid membranes, because it is highly symmetric and lipophilic. Therefore, we investigated conformational properties of and metal-ion transport by synthetic cyclic octapeptide, cyclo(D-Leu-L-Pro) ${ }_{4}$.

The mechanism of ion transport through biological membranes mediated by channel-forming peptides such as gramicidine $\mathrm{A}^{5}$ and alamethicin has 
not been well understood. In the present study, sequential oligopeptides Boc-(Leu-Leu-D-PhePro $)_{n}$-OBzl $(n=1,2,3$, and 4$)$ and a sequential polypeptide, poly(Leu-Leu-D-Phe-Pro) were synthesized, which contain a part of $\beta$-turn sequence in gramicidine $\mathrm{S}$ and are expected to have successive $\beta$ turns with a large internal diameter as models for ion channel. We investigated conformation of sequential polypeptide poly(Leu-Leu-D-Phe-Pro) and formation of ion channel across bilayer lipid membrane (BLM).

Transmembrane glycoproteins ${ }^{6}$ are important components of cell membranes, acting as receptors for numerous external agents such as plant lectins, ${ }^{7}$ viruses and hormones. A glycodipeptide (CC2), in which $\mathrm{N}$-acetyl-D-glucosamine is substituted at $\mathrm{C}_{1}$ site with a chromophoric dipeptide, was synthesized. This sugar group is specific for wheat germ agglutinin (WGA), ${ }^{8}$ which is a lectin from tritcum vulgaris, but not specific for phytohemagglutinin (PHA), which is a lectin from phaseolus vulgaris. The response of $\mathrm{CC} 2$ in vesicles to lectins was investigated by spectroscopic methods.

\section{EXPERIMENTAL}

Cyclo(D-Leu-L-Pro) ${ }_{4}$ was synthesized, as shown in Figure 1, by cyclization of the linear oligopeptide under high dilution, which was prepared by the fragment condensation.

Conformation of cyclo(D-Leu-L-Pro $)_{4}$ in solution was investigated by nuclear magnetic resonance (NMR) and circular dichroism (CD) spectroscopy.
The state of hydrogen bonding of cyclo(D-Leu-LPro $)_{4}$ was investigated by $\mathrm{H}-\mathrm{D}$ exchange reaction. The metal ion transport by cyclo(D-Leu-L-Pro) ${ }_{4}$ $\left(140 \mu \mathrm{mol} \mathrm{dm}^{-3}\right)$ through $\mathrm{CH}_{2} \mathrm{Cl}_{2}$ or $\mathrm{CHCl}_{3}$ membrane $\left(20 \mathrm{~cm}^{3}\right)$ was measured using U-shaped tube. ${ }^{9}$ Metal chloride $\left(10 \mathrm{mmol} \mathrm{dm}^{-3}\right)$ and picric acid $(25$ mmol $\mathrm{dm}^{-3}$ ) were dissolved in aqueous phase I $\left(15 \mathrm{~cm}^{3}, \mathrm{pH} 7.2\right)$, and the ion transport was monitored by the absorption of picrate anion in aqueous phase II $\left(15 \mathrm{~cm}^{3}\right)$. Calcium ion transport across the liposomal membrane by cyclo(D-Leu-L-Pro) ${ }_{4}(5-10$ $\mu \mathrm{mol} \mathrm{dm}^{-3}$ ) was judged by fluorescence of chlorotetracyclin, which fluoresces upon coordination with a divalent metal cation. ${ }^{10} \mathrm{~A}$ dispersion of liposomes of dipalmitoyl phosphatidyl choline (DPPC) $\left(1 \mathrm{mmol} \mathrm{dm}{ }^{-3}\right)$ was prepared by sonication. In the interior aqueous phase, chlorotetracyclin $(2.5 \times$ $10^{-5} \mathrm{~mol} \mathrm{dm}^{-3}$ ) was dissolved. In the aqueous phase outside the liposomes, calcium picrate (1 mmol dm ${ }^{-3}$ ) was present.

Sequential oligopeptides Boc-(Leu-Leu-D-PhePro $)_{n}$-OBzl ( $n=1,2,3$, and 4$)$ and a sequential polypeptide poly(Leu-Leu-D-Phe-Pro) were synthesized by the scheme shown in Figure 2.

Conformation of the sequential oligopeptides and the sequential polypeptide in solution was investigated by NMR and CD spectroscopy. The state of hydrogen bonding was investigated by infrared (IR) and NMR spectroscopy and the space-filling molecular model. Ion gating in BLM by the sequential polypeptide was investigated as follows. An electric cell was filled with aqueous solution $(\mathrm{pH}$ 6.8, 0.5 mol $\mathrm{dm}^{-3} \mathrm{KCl}$, tris buffer) and divided into two





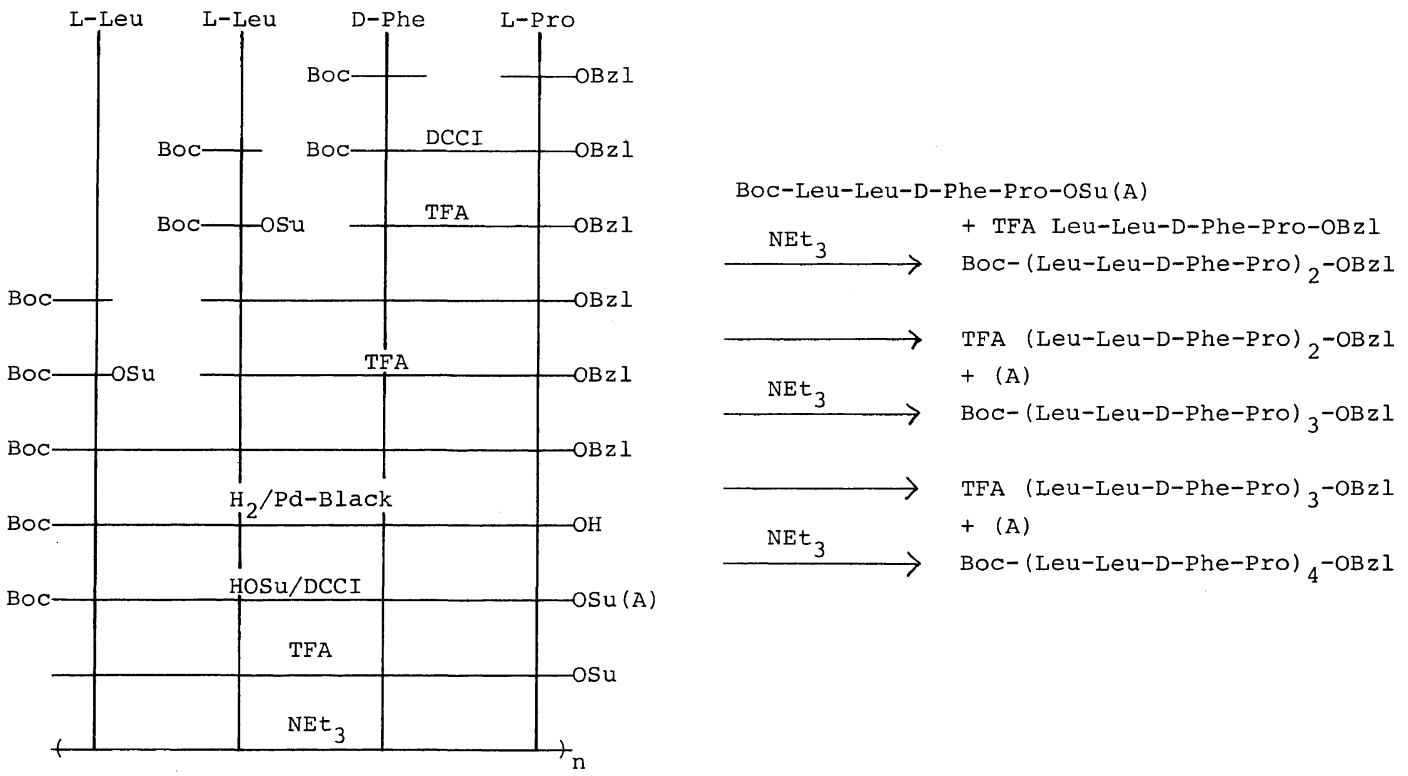

Figure 2. Synthetic scheme of poly(Leu-Leu-D-Phe-Pro) and Boc-(Leu-Leu-D-Phe-Pro $)_{n}$-OBzl $(n=1,2$,

3 , and 4).

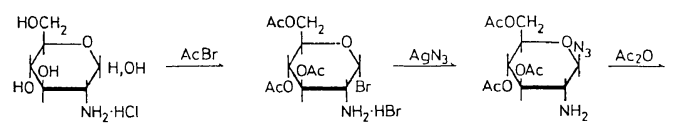

$\begin{array}{lll}\mathrm{NHAC} & \end{array}$

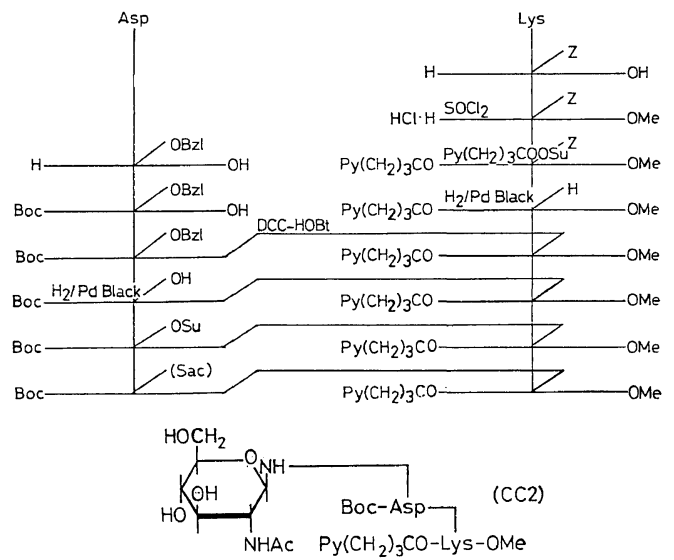

Figure 3. Synthetic scheme of glycodipeptide CC2. halves with an oxidized cholesterol membrane. A trifluoroethanol (TFE) solution of the sequential polypeptide was added in the positive chamber under an application of electric field, and the current-voltage response was recorded.

A linear glycodipeptide (CC2), Boc-Asp ( $\beta$-COX)$\varepsilon$-Lys $(\alpha-\mathrm{NHY})-\mathrm{OMe}$ in which $\mathrm{X}$ represents $1-\beta$ amino-acetylglucosamine group and $\mathrm{Y}$ represents pyrene butyryl group, was synthesized according to the scheme of Figure 3.

Vesicles of dimyristoyl, dipalmitoyl, and distearoyl phosphatidyl choline (DMPC, DPPC, and DSPC) were prepared as follows. Lipids were dissolved in chloroform and a thin film of lipid was obtained by evaporation. To the film buffered aqueous solution was added and the suspension was sonicated at temperatures higher by $10^{\circ} \mathrm{C}$ than phase-transition temperatures $\left(T_{\mathrm{c}}\right)$. Ultracentrifugation $\left(10^{5} \mathrm{~g}, 0.5 \mathrm{~h}\right)$ gave a small unilamellar vesicle (SUV). Large unilamellar vesicles (LUV) with $0.1 \mu \mathrm{m}$ diameter were prepared according to the method reported by Szoka, Jr. et al. ${ }^{11}$

Aggregation of CC2-containing vesicles induced by lectins and segregation induced by inhibitors were monitored by the change of turbidity. Intravesicular association of $\mathrm{CC} 2$ was monitored by the increase of emission intensity due to pyrene 
excimer $\left(I_{\mathrm{D}}\right)$ over that due to pyrene monomer $\left(I_{\mathrm{M}}\right)$. The change of membrane fluidity at the surface of vesicle induced by the addition of $\mathrm{CC} 2$ and lectin was investigated by the fuorescence polarizability of 8-anilinonaphthalene sulfonic acid (ANS), and that in the bulk of vesicle by the fluorescence polarizability of 1,6-diphenylhexatriene (DPH). ${ }^{12}$

\section{RESULTS AND DISCUSSION}

Conformational Properties of and Metal Ion Transport by Synthetic Carrier Ionophore, Cyclic Octapeptide, Cyclo(D-Leu-L-Pro $)_{4}$

Conformation of cyclo(D-Leu-L-Pro) $)_{4}$ in solution was investigated by spectroscopy. The $\mathrm{NH}$ region of ${ }^{1} \mathrm{H}$ NMR spectrum of cyclo(D-Leu-L-Pro) ${ }_{4}$ in $\mathrm{CD}_{2} \mathrm{Cl}_{2}$ is shown in Figure 4. The spectrum at $30^{\circ} \mathrm{C}$ is characteristic of all-trans $\mathrm{C}_{4}$ - symmetric conformation, as evidenced by the single $\mathrm{NH}$ signal. Lowering the temperature, the $\mathrm{NH}$ signal disappeared at $-30^{\circ} \mathrm{C}$ and reappeared at $\delta 5.5$ and 7.5 at lower temperatures. In the $\mathrm{C}=\mathrm{O}$ region of ${ }^{13} \mathrm{C}$ NMR spectrum, as shown also in Figure 4, one and four signals were observed at 30 and $-80^{\circ} \mathrm{C}$, respectively. These observations can be explained in terms of a rapid conformational averaging of cyclo(D-Leu-L-Pro) ${ }_{4}$ taking place at room temperature.

CD spectral change of cyclo(D-Leu-L-Pro $)_{4}$ took place in alcoholic solution by the addition of $\mathrm{Ca}^{2+}$ and $\mathrm{Ba}^{2+}$, which indicates metal ion binding by the cyclic octapeptide accompanying a conformational change. $C D$ spectral change was not induced by the addition of $\mathrm{K}^{+}, \mathrm{Na}^{+}, \mathrm{Mg}^{2+}, \mathrm{Ag}^{+}$, and $\mathrm{Cd}^{2+}$ indicating an ion-selective binding. It is contrasting that CD spectrum of cyclo(L-Leu-L-Pro $)_{4}$ in alcoholic solution changed by the addition of $\mathrm{K}^{+}{ }^{3}$ The binding constant was calculated from the variation of the molar ellipticity of CD spectrum. Thus the binding constant of cyclo(D-Leu-L-Pro $)_{4}$ with $\mathrm{Ba}^{2+}$ was determined to be $400 \mathrm{dm}^{-3} \mathrm{~mol}^{-1}$, which is nearly the same as $360 \mathrm{dm}^{3} \mathrm{~mol}^{-1}$ reported for cyclo(L-Leu-L-Pro) ${ }_{4} / \mathrm{Ba}^{2+}$ complex. ${ }^{3}$ The rate constant of complex formation of cyclo(D-Leu-L-Pro) ${ }_{4}$ with $\mathrm{Ba}^{2+}$ in $\mathrm{MeOH}-\mathrm{H}_{2} \mathrm{O}(95: 5, \mathrm{v} / \mathrm{v})$ was determined from time-resolved ellipticity of $\mathrm{CD}$ spectrum to be larger than $2 \times 10^{3} \mathrm{dm}^{3} \mathrm{~mol}^{-1} \mathrm{~min}^{-1}$. This is much larger than $0.7 \mathrm{dm}^{3} \mathrm{~mol}^{-1} \mathrm{~min}^{-1}$ reported for cyclo(L-Leu-L-Pro) $)_{4}$ and $\mathrm{Ba}^{2+} .^{3}$ It was found by NMR spectroscopy that cyclo(D-Leu-L-

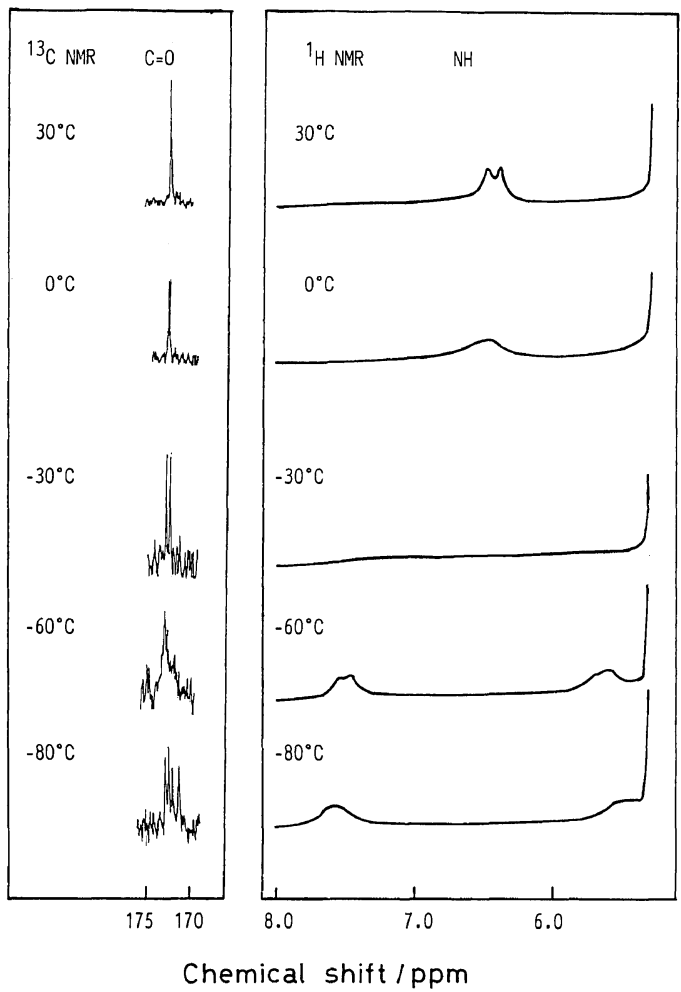

Figure 4. ${ }^{1} \mathrm{H}$ and ${ }^{13} \mathrm{C}$ NMR spectra of cyclo(D-Leu-LPro) $)_{4}$ in $\mathrm{CD}_{2} \mathrm{Cl}_{2}$ at different temperatures.



Figure 5. Time course of $\mathrm{H}-\mathrm{D}$ exchange of amide $\mathrm{NH}$ : $\square, \quad$ cyclo(D-Leu-L-Pro) $)_{4} ; \quad \bigcirc, \quad$ cyclo(D-Leu-L-Pro $)_{4}+$ $\mathrm{Ba}\left(\mathrm{ClO}_{4}\right)_{2} ; \triangle, N$-methylacetamide.

Pro) $)_{4} / \mathrm{Ba}^{2+}$ complex took an all-trans $\mathrm{C}_{4}$-symmetric conformation.

Figure 5 shows the time course of $\mathrm{H}-\mathrm{D}$ exchange of cyclo(D-Leu-L-Pro) $)_{4}$ in $\mathrm{CDCl}_{3}$ containing $\mathrm{CD}_{3} \mathrm{OD}(40 \mathrm{eq} / \mathrm{NH}) .{ }^{13}$ The half life of unexchanged $\mathrm{NH}$ is 31 and $15 \mathrm{~min}$ for the free peptide and the 


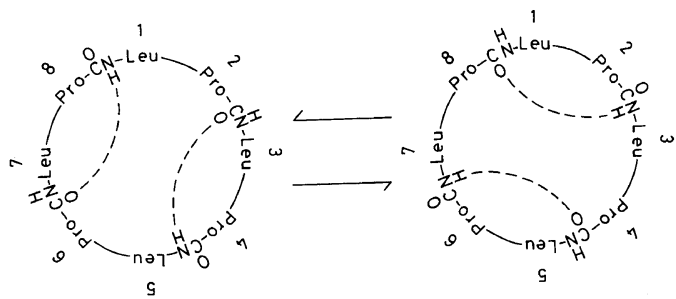

Figure 6. Conformational equilibrium between two $\mathrm{C}_{2}$-symmetric conformers of cyclo(D-Leu-L-Pro) ${ }_{4}$ in $\mathrm{CH}_{2} \mathrm{Cl}_{2}$.



Figure 7. Ion transport across $\mathrm{CHCl}_{3}$ membrane by cyclo(D-Leu-L-Pro) ${ }_{4}: \bigcirc, \mathrm{Ba}^{2+} ; \square, \mathrm{Ca}^{2+} ; \triangle, \mathrm{K}^{+}$.

$\mathrm{Ba}^{2+}$ complex, respectively. The latter value is nearly the same as the half life of $N$-methylacetamide, indicating that the probability of peptide hydrogens involved in the free peptide being exposed to solvent is half as large as that for the $\mathrm{Ba}^{2+}$ complex.

It was concluded on the basis of these experimental results that free cyclo(D-Leu-L-Pro) ${ }_{4}$ assumes two $\mathrm{C}_{2}$-symmetric conformations and a rapid interchange between them takes place as shown in Figure 6 at room temperature. Free energy of the conformational change was determined to be ca. $3 \mathrm{kcal} \mathrm{mol}^{-1}$ by ${ }^{1} \mathrm{H}$ NMR spectroscopy, which indicates that the conformational change does not involve the isomerization of peptide bonds.

The efficient and fast binding of metal ion accompanying the scission of internal hydrogen bonding and the internal rotation of single bonds as well as the high lipophilicity of the metal ion complex represents promising properties of cyclo(D-Leu-LPro $)_{4}$ as a synthetic ionophore.

The metal ion transport through a liquid membrane was investigated. The amounts of metal ions transported across $\mathrm{CHCl}_{3}$ membrane by cyclo(D-

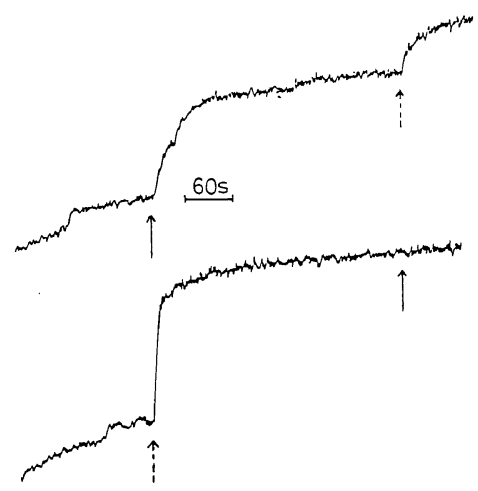

Figure 8. Time-dependent increases in chlorotetracyclin- $\mathrm{Ca}^{2+}$ fluorescence on adding ionophore. Ionophore addition marked with an arrow, cyclo(D-LeuL-Pro) $)_{4}, 6 \mu \mathrm{mol} \mathrm{dm}^{-3}$ and with a broken arrow, X537A, $10 \mu \mathrm{mol} \mathrm{dm}^{-3}$.

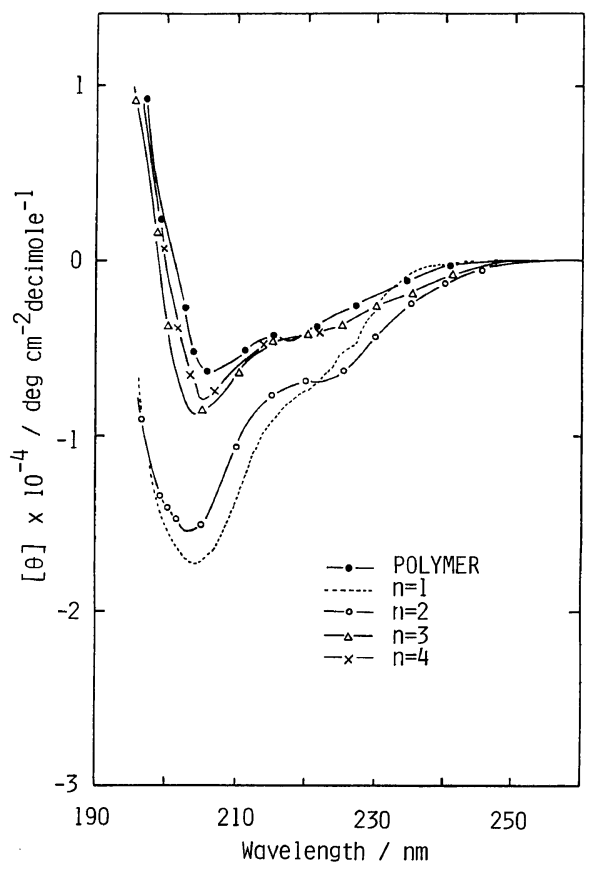

Figure 9. CD spectra of Boc-(Leu-Leu-D-Phe-Pro) ${ }_{n}$ OBzl ( $n=1,2,3$, and 4) and poly(Leu-Leu-D-phe-Pro) ${ }_{n}$ in $\mathrm{CF}_{3} \mathrm{CH}_{2} \mathrm{OH}$ : conc., $0.3 \mathrm{mg} \mathrm{cm}-3$; room temp.

Leu-L-Pro $)_{4}$ are shown in Figure 7. $\mathrm{Ba}^{2+}$ was transported most efficiently. The same selectivity has been observed for cyclo(D-Leu-L-Pro $)_{4} \cdot{ }^{4}$ The $\mathrm{K}^{+}$transport by cyclo(D-Leu-L-Pro) ${ }_{4}$ was about $1 / 3$ times as effective as that by dicyclohexyl 18-crown-6 under similar conditions. ${ }^{14}$ Although $\mathrm{Ca}^{2+}$ was a 
specific guest ion for cyclo(D-Leu-L-Pro $)_{4}, \mathrm{Ca}^{2+}$ transport across $\mathrm{CHCl}_{3}$ membrane by cyclo(D-LeuL-Pro $)_{4}$ was not efficient. The extraction coefficient from aqueous phase to organic phase and the rate of complexation should be more closely related to the efficiency of ion transport than the equilibrium binding constant in the organic phase.

$\mathrm{Ca}^{2+}$ transport across DPPC membrane by cyclo(D-Leu-L-Pro) ${ }_{4}$ was investigated by fluorescence of chlorotetracyclin. When cyclo(D-Leu-LPro $)_{4}$ was added to the dispersion of DPPC liposomes in aqueous solution containing calcium picrate, chlorotetracyclin contained in the internal aqueous phase of liposome fluoresced as shown in Figure 8, indicating ion transport across the liposomal membrane.

Conformation of Sequential Polypeptides Poly(LeuLeu-D-Phe-Pro) and Formation of Ion Channel across BLM

CD spectra of Boc(Leu-Leu-D-Phe-Pro $)_{n}$-OBzl
( $n=1,2,3$, and 4) and poly(Leu-Leu-D-Phe-Pro) in TFE are shown in Figure 9. $[\theta]_{207}$ decreased and the shoulder at $220 \mathrm{~nm}$ became more marked with increasing chain length of the peptide. This change could be interpreted in terms of the stabilization of a regular structure. The pattern of $C D$ spectrum of poly(Leu-Leu-D-Phe-Pro) is similar to the oligopeptides with $n=3$ and 4 , suggesting a similar conformation in solution. Boc-(Leu-Leu-D-Phe-Pro) ${ }_{3}$ OBzl changed the conformation in THF depending on temperature, and Boc-(Leu-D-Phe-Pro) ${ }_{4}$-OBzl took different conformations in polar and nonpolar solvents. In the amide $\mathrm{NH}$ and $\mathrm{C}^{\alpha} \mathrm{H}$ regions of ${ }^{1} \mathrm{H}$ NMR spectrum of poly(Leu-Leu-D-Phe-Pro) in $\mathrm{CDCl}_{3}$, a drastic change was observed on adding trifluoroacetic acid (TFA). These findings point to a certain secondary conformation of the sequential peptides in nonpolar solvents.

As shown in ${ }^{13} \mathrm{C}$ NMR spectra of Figure 10, the oligopeptides Boc-(Leu-Leu-D-Phe-Pro) ${ }_{n}$-OBzl $(n=$ 1 and 2) took multiple conformations in $\mathrm{CDCl}_{3}$



Figure 10. ${ }^{13} \mathrm{C}$ NMR spectrum of Boc-(Leu-Leu-D-Phe-Pro) ${ }_{n}-\mathrm{OBzl}$. (a) $n=1,170 \mathrm{mg} \mathrm{cm}^{-3}$, (b) $n=2$, $70 \mathrm{mg} \mathrm{cm}^{-3}$, (c) $n=3,70 \mathrm{mg} \mathrm{cm}{ }^{-3}$, and (d) poly(Leu-Leu-D-Phe-Pro), $33 \mathrm{mg} \mathrm{cm}^{-3}$ in $\mathrm{CDCl}_{3}$ at $30^{\circ} \mathrm{C}$. 




a

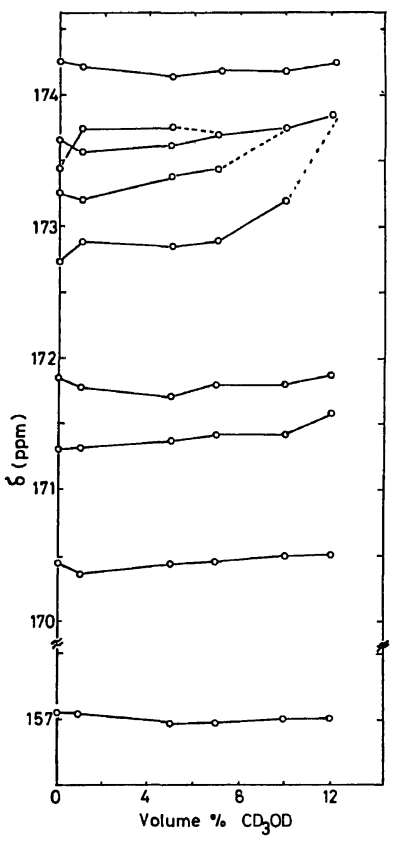

b

Figure 11. Change of chemical shift in ${ }^{1} \mathrm{H}$ and ${ }^{13} \mathrm{C}$ NMR of Boc-(Leu-Leu-D-Phe-Pro) ${ }_{3}-\mathrm{OBzl}$ in $\mathrm{CDCl}_{3}$ $\left(10 \mathrm{mg} \mathrm{cm}^{-3}\right)$ by the addition of methanol $\left(1-5 \mathrm{vol} \%\right.$ ) at $25^{\circ} \mathrm{C}$. (a) $400 \mathrm{MHz}{ }^{1} \mathrm{H} \mathrm{NMR}$; (b) ${ }^{13} \mathrm{C} \mathrm{NMR}$.

according to the cis/trans isomerization of Propeptide bonds and that Boc-(Leu-Leu-D-Phe-Pro) ${ }_{3}{ }^{-}$ OBzl and poly(Leu-Leu-D-Phe-Pro) took similar conformations in which Pro-peptide bonds were confined to take trans configuration. The above experimental results indicate that the conformation in solution of poly(Leu-Leu-D-Phe-Pro) can be identified by the investigation on the conformation of Boc-(Leu-Leu-D-Phe-Pro) ${ }_{3}$-OBzl.

In order to investigate the exposure to solvent of amide and urethane linkages of Boc-(Leu-Leu-DPhe-Pro) ${ }_{3}$-OBzl, shifts of ${ }^{1} \mathrm{H}$ NMR signals (Figure 11a) and ${ }^{13} \mathrm{C}$ NMR signals (Figure $11 \mathrm{~b}$ ) induced by the addition of methanol to $\mathrm{CDCl}_{3}$ solution of Boc(Leu-Leu-D-Phe-Pro) ${ }_{3}$-OBzl were measured. These experimental results showed that two LeuNHs are exposed to solvent and the urethane carbonyl group is shielded from solvent.

IR spectroscopy on $\mathrm{CDCl}_{3}$ solutions of Boc(Leu-Leu-D-Phe-Pro) ${ }_{n}$-OBzl $(n=1,2,3$, and 4) and poly(Leu-Leu-D-Phe-Pro) (see Figure 12) revealed that $\mathrm{NH}$ protons of the oligopeptide with $n=1$ are free from hydrogen bonding, those with $n=2,3$, and 4 are partly hydrogen bonded, and those of



Figure 12. Amide $A$ absorption regions of IR spectra of Boc-(Leu-Leu-D-Phe-Pro) ${ }_{n}$-OBzl and poly(Leu-LeuD-Phe-Pro) in $\mathrm{CDCl}_{3}\left(\right.$ ca. $\left.1 \times 10^{-3} \mathrm{~mol} \mathrm{dm}^{-3}\right)$. 
Table I. Hydrogen-bonding characteristics for various conformations of Boc-(Leu-Leu-D-Phe-Pro) ${ }_{3}$-OBzl

\begin{tabular}{|c|c|c|c|}
\hline Conformation & H-bond-free $\mathrm{NH}$ & Urethane $\mathrm{NH}$ & Urethane $\mathrm{C}=\mathrm{O}$ \\
\hline$\alpha$-Helix & $\mathrm{Leu}^{1}, \mathrm{Leu}^{2}, \mathrm{D}-\mathrm{Phe}^{3}$ & Not H-bonded & Not H-bonded \\
\hline $3_{10}-$ Helix & $\mathrm{Leu}^{1}, \mathrm{Leu}^{2}$ & Not H-bonded & H-bonded \\
\hline$\beta^{4.4}-$ Helix $^{\mathrm{a}}$ & $\mathrm{Leu}^{1}, \mathrm{Leu}^{2}, \mathrm{D}-\mathrm{Ph} \mathrm{e}^{3}$ & Not $\mathrm{H}$-bonded & H-bonded \\
\hline$\beta^{6.3}$-Helix ${ }^{b}$ & $\mathrm{Leu}^{1}, \mathrm{Leu}^{2}, \mathrm{D}-\mathrm{Phe}^{3}$, & Not H-bonded & H-bonded \\
\hline & $\mathrm{Leu}^{5}, \mathrm{Leu}^{6}$ & Not H-bonded & \\
\hline $\begin{array}{l}\uparrow \downarrow \beta^{5.6} \text {-Helix } \\
\text { (left hand) }\end{array}$ & $\mathrm{Leu}^{2}$ & H-bonded & Not H-bonded \\
\hline $\begin{array}{l}\uparrow \downarrow \beta^{5.6} \text {-Helix } \\
\quad \text { (right hand) }\end{array}$ & Leu $^{1}$, D-Phe ${ }^{3}$ & Not H-bonded & Not H-bonded \\
\hline
\end{tabular}

a $6 \rightarrow 1$ hydrogen-bonding.

b $8 \rightarrow 1$ hydrogen bonding.

polypeptide are completely hydrogen bonded. From the measurements at different concentrations of Boc-(Leu-Leu-D-Phe-Pro) ${ }_{4}$-OBzl, the hydrogen bonding was concluded to be intramolecular.

The states of hydrogen bonding in possible conformations of Boc-(Leu-Leu-D-Phe-Pro) ${ }_{3}$-OBzl were considered and are listed in Table I. The agreement of Table I with the information from ${ }^{1} \mathrm{H}$ NMR spectroscopy is obtained only with $3_{10}$-helix, leading to the conclusion that Boc-(Leu-Leu-D-Phe-Pro) ${ }_{3}$ OBzl takes $3_{10}$-helix conformation in $\mathrm{CDCl}_{3}$. The $3_{10}$-helix has been often found in Aib-containing peptides, ${ }^{15,16}$ and is formed by the continuation of the $4 \rightarrow 1$ hydrogen bonds of type III $\beta$-turn. ${ }^{17}$ When a Pro residue is involved in $33_{10}$-helix, ${ }^{13} \mathrm{C}$ NMR chemical shift of $\mathrm{C}^{\alpha}$ shifts to lower magnetic field than $60 \mathrm{ppm},{ }^{17}$ which was the present case. The present conclusion is that the sequential polypeptide, poly(Leu-Leu-D-Phe-Pro), takes $3_{10}$-helix conformation in $\mathrm{CDCl}_{3}$.

The current trace recording of poly(Leu-Leu-DPhe-Pro) in the oxidized cholesterol membrane is shown in Figure 13.

The current-voltage response across the membrane was observed. At $75 \mathrm{mV}$, an electric current of $55 \mathrm{pA}$ was observed after $20-30 \mathrm{~min}$. However, fluctuation in current was observed and the current disappeared by the prolonged application of $75 \mathrm{mV}$. On the other hand, by the application of $-75 \mathrm{mV}$ a stationary current of about $-55 \mathrm{pA}$ was observed. In this case fluctuation of current was not observed. In the stationary state the current-voltage relation showed the Ohmic behavior as shown in Figure 14.

With increasing $\mathrm{KCl}$ concentration from $0.5 \mathrm{~mol}$
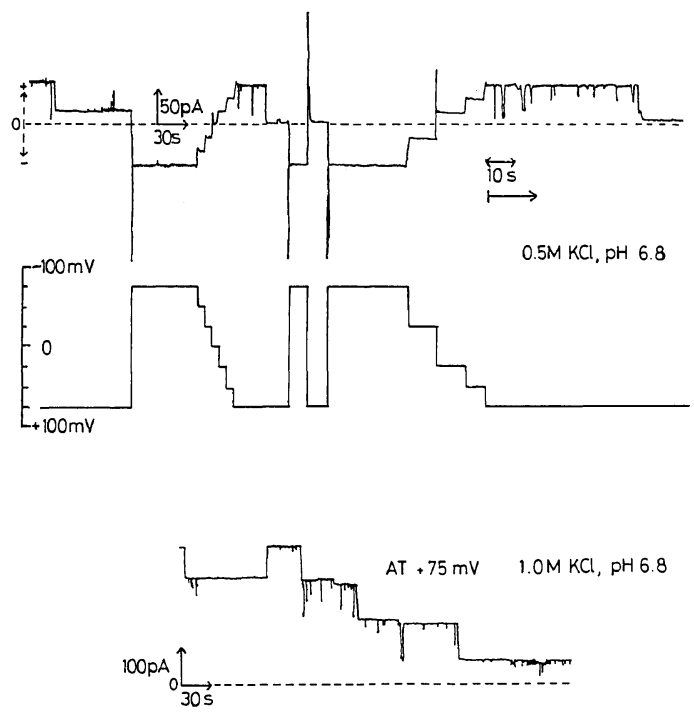

Figure 13. Current trace recording of poly(Leu-Leu-DPhe-Pro) in oxidized cholesterol membrane.

$\mathrm{dm}^{-3}$ to $1.0 \mathrm{~mol} \mathrm{dm}{ }^{-3}$ the magnitude of the discrete current jump became about $100 \mathrm{pA}$. This observation suggests a formation of channels having a definite pore size.

In a $3_{10}$-helix, the pitch per a residue is $2 \AA$. Since the thickness of oxidized cholesterol membrane is $40-60 \AA$, a $33_{10}$-helix consisting of $20-30$ residues is necessary to penetrate the membrane. The molecular weight of the present poly(Leu-Leu-D-PhePro) lies between 15,000 and 25,000 indicating the numbers of residue to be $130-200$. It is considered that by the application of electric field the polypep- 




Figure 14. Current-voltage relationship for an oxidized cholesterol membrane treated with poly(Leu-LeuD-Phe-Pro). - , pore open; ---, pore closed.

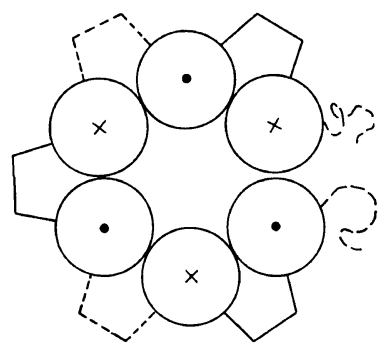

Figure 15. Proposed model for a channel formed by poly(Leu-Leu-D-Phe-Pro). Cross section in the plane of the membrane.

tide folds into a bundle of at least six $3_{10}$-helices, as depicted in Figure 15. We see the bundle of $3_{10^{-}}$. helices from the top to the bottom or vice versa. In this model, adjacent 310 -helices run in opposite directions. Ions permeate through the central cavity with coordination to peptide bonds. Incorporation of the sequential polypeptide into BLM should be vectorial, so that a discrete current jump was observed by an electric field having a minus sign. Application of electric field having a positive sign caused a fluctuation and disappearance of current. This type of channel should lead to a constant pore size, which is different from that formed by intermolecular association of helical chains as in the case of alamethicin. ${ }^{18}$

Interactions of Synthetic Glycopeptides with Lectins in Lipid Bilayer Membranes

Using fluorescent quenching with acrylamide, the incorporation of CC2 into DMPC, DPPC, and

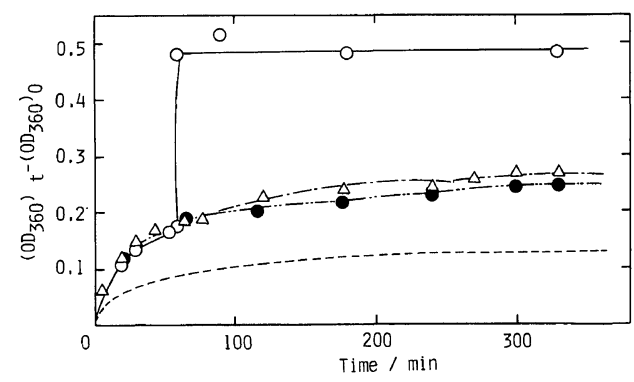

Figure 16. Aggregation of DPPC LUV $\left(1 \mathrm{mmol} \mathrm{dm}^{-3}\right)$ containing CC2 $\left(1.65 \times 10^{-5} \mathrm{~mol} \mathrm{dm}^{-3}\right)$ by lectin at room temperature. --- , liposome only; $-\cdot-\Delta-\cdot-$, liposome + CC2; - O-, liposome + CC2 + WGA $\left(3.3 \times 10^{-7} \mathrm{~mol} \mathrm{dm}^{-3}\right),-\cdots-\cdots-$, liposome $+\mathrm{CC} 2+$ PHA $\left(8.7 \times 10^{-8} \mathrm{~mol} \mathrm{dm}^{-3}\right)$.



Figure 17. Segregation of associated DPPC LUV by inhibitor for lectin at room temperature. ---, liposome only; $-\cdot-\triangle^{-\cdot}-$, liposome $+\mathrm{CC} 2+$ GlcNAc; $-\mathrm{O}-$, liposome + CC2 + WGA + GlcNAc; - - - - liposome + CC2 + PHA + GlcNAc.

DSPC vesicles was confirmed. When WGA was added to the dispersion of vesicles containing $\mathrm{CC} 2$, the turbidity increased drastically, as shown in Figure 16, which indicates intervesicular aggregation taking place. This turbidity change represents a specific interaction of the sugar group of CC2 with WGA, because the change of turbidity was not observed when PHA was added to the dispersion of vesicles containing $\mathrm{CC} 2$.

As evidenced by the sudden decrease of turbidity shown in Figure 17, the vesicular aggregation was segregated by the addition of $N$-acetyl-Dglucosamine (GlcNAc), which is an inhibitor of WGA, but not by the addition of $\mathrm{N}$-acetyl-Dgalactosamine (GalNAc), which is an inhibitor of PHA. The segregation by GlcNAc proves that the turbidity increase by WGA (Figure 16) was caused by the aggregation of vesicles and not by the fusion 


\section{Y. IMANISHI}
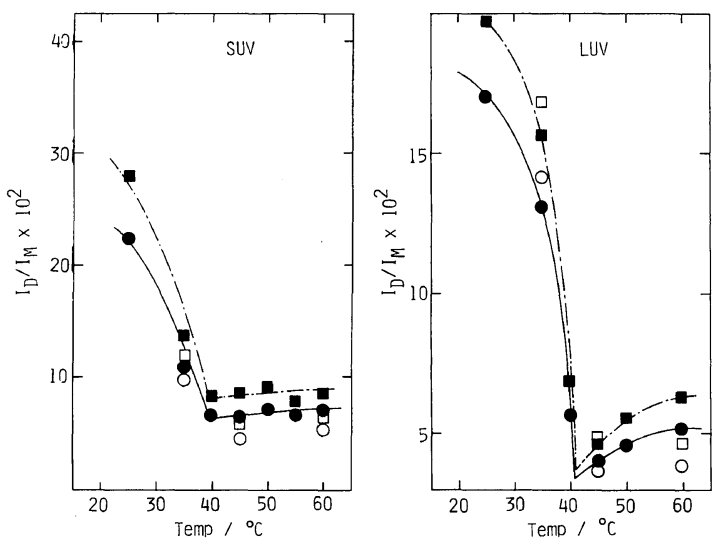

Figure 18. Phase separation of DPPC liposomes $\left.(1 \mathrm{mmol} \mathrm{dm})^{-3}\right)$ induced by CC2 $\left(1.9 \times 10^{-5} \mathrm{~mol}\right.$ $\left.\mathrm{dm}^{-3}\right) . I_{\mathrm{D}}, 480 \mathrm{~nm} ; I_{\mathrm{M}}, \bigcirc$ and $\bigcirc 376 \mathrm{~nm} ; \square$ and $\square 397 \mathrm{~nm} ; \bigcirc$ and $\square$, temperature rising; $\bigcirc$ and $\square$, temperature lowering.
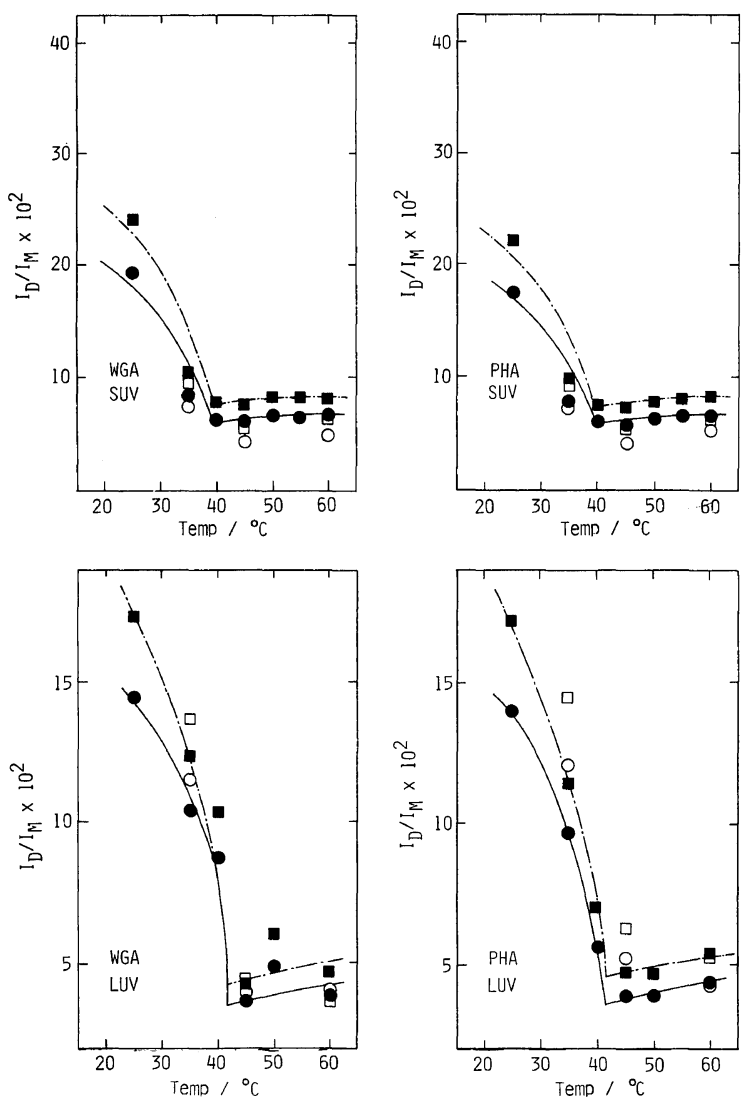

Figure 19. Lectin-induced intravesicular aggregation of CC2 $\left(1.65 \times 10^{-5} \mathrm{~mol} \mathrm{dm}^{-3}\right)$ in DPPC liposomes. $[\mathrm{WGA}]=1 \times 10^{-6} \mathrm{~mol} \mathrm{dm}{ }^{-3}$. $[\mathrm{PHA}]=1.74 \times 10^{-7} \mathrm{~mol} \mathrm{dm}^{-3}$. Notations are the same as those in Figure 18. 
of vesicles. These experimental results also confirm the specific interaction of $\mathrm{CC} 2$ embeded in vesicles with WGA.

By fluorescent spectroscopy the ratio of $I_{\mathrm{D}}$ over $I_{\mathrm{M}}$ of $\mathrm{CC} 2$ was determined in the temperature range from 25 to $60^{\circ} \mathrm{C}$. In the HEPES-buffered saline solution at $\mathrm{pH} 7.4, I_{\mathrm{D}} / I_{\mathrm{M}}$ did not change with the temperature change. However, as shown in Figure 18 , in the DPPC vesicular system $I_{\mathrm{D}} / I_{\mathrm{M}}$ changed sharply at $T_{\mathrm{c}}$. From the effect of temperature on the quantum yield of monomer and excimer fluorescence both in solution and vesicular systems, it was concluded that below $T_{\mathrm{c}}, \mathrm{CC} 2$ formed an excimer

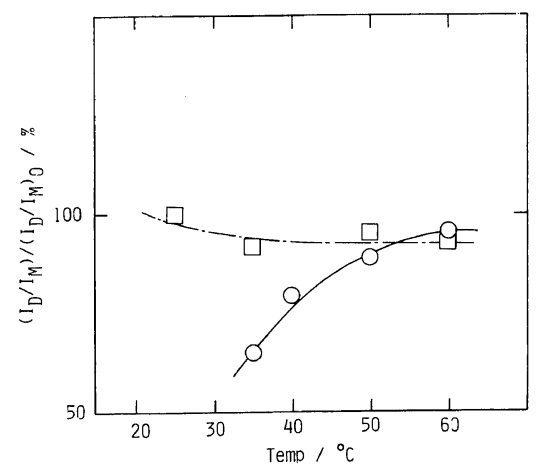

Figure 20. Lectin-induced release of $\mathrm{CC} 2$ from DPPC SUV $\left(1 \mathrm{mmol} \mathrm{dm}^{-3}\right)$. - - -, liposome + $\mathrm{CC} 2+$ WGA; - $\cdot-\square-\cdot-$, liposome $+\mathrm{CC} 2+\mathrm{PHA} ;\left(I_{\mathrm{D}} / I_{\mathrm{M}}\right)_{0}$, liposome $+\mathrm{CC} 2 ; I_{\mathrm{M}}, 367 \mathrm{~nm}$ by patching phenomenon ${ }^{19}$ due to phase separation of lipid membrane.

It was expected that WGA might induce an intravesicular interaction of $\mathrm{CC} 2$ to result in the increment of $I_{\mathrm{D}} / I_{\mathrm{M}}$. However, as shown in Figure 19, a little decrease of $I_{\mathrm{D}} / I_{\mathrm{M}}$ was observed on adding WGA.

To eliminate complexities arising from the disordering of the lipid bilayer structure at $T_{\mathrm{c}}, I_{\mathrm{D}} / I_{\mathrm{M}}$ in the presence of lectin was determined at different temperatures. As shown in Figure 20, the relative intensity ratio was nearly unity at any temperatures when PHA was used, whereas it decreased from unity below $T_{\mathrm{c}}$ when WGA was used. These experimental results are explained in terms of the partial abstraction of CC2 by WGA from the BLM. This explanation was supported by the quenching of the monomer fluorescence of $\mathrm{CC} 2$-containing liposomal system with acrylamide on adding WGA.

The change of membrane fluidity induced by the addition of $\mathrm{CC} 2$ and lectin was investigated and the results are shown in Figure 21.

The addition of $\mathrm{CC} 2$ was found to decrease the membrane fluidity, which might be due to the formation of gel-like domain. The addition of WGA to the vesicles containing $\mathrm{CC} 2$ increased the membrane fluidity, whereas PHA had little effect. Therefore, the fluidity increase is due to a specific interaction between $\mathrm{CC} 2$ and WGA, such as an intravesicular crosslinking of $\mathrm{CC} 2$ with lectin lead-
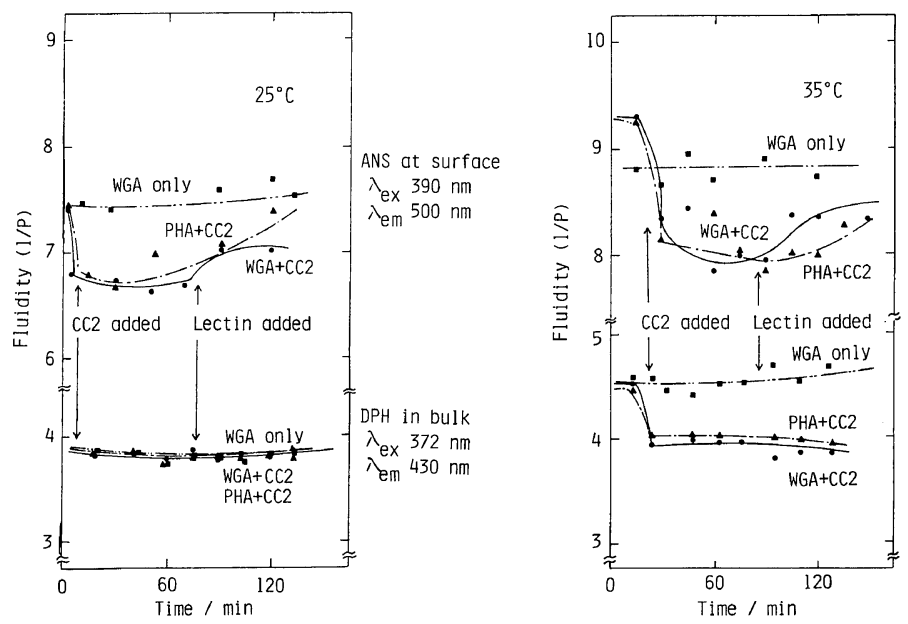

Figure 21. Change of membrane fluidity of DPPC SUV $\left(1 \mathrm{mmol} \mathrm{dm}{ }^{-3}\right)$ by CC2 $\left(1.9 \times 10^{-5} \mathrm{~mol} \mathrm{dm}^{-3}\right)$ and lectins below $T_{\mathrm{c}}$. [WGA] $=3.3 \times 10^{-7} \mathrm{~mol} \mathrm{dm}^{-3},[\mathrm{PHA}]=8.7 \times 10^{-8} \mathrm{~mol} \mathrm{dm}^{-3},[\mathrm{ANS}]=1.6 \times 10^{-4}$ $\mathrm{mol} \mathrm{dm}{ }^{-3},[\mathrm{DPH}]=1.6 \times 10^{-5} \mathrm{~mol} \mathrm{dm}{ }^{-3}$. 
ing to an increase of fluid regions of membrane. This idea received a support from the experimental result that the fluidity increase was also observed with a chromophoric dipeptide with carboxyl group but without sugar group, $\mathrm{Py}\left(\mathrm{CH}_{2}\right)_{3} \mathrm{CO}$-Lys-( $(\varepsilon-\mathrm{Boc}-$ Asp) $-\mathrm{OCH}_{3}$, interacting with divalent cations in liposome. The absence of the increase of excimer formation between $\mathrm{CC} 2$ molecules induced by WGA in liposome in spite of the crosslinking might be due to chromophoric groups being kept too distantly to form an excimer. On the other hand, the addition of WGA to the vesicles containing $\mathrm{CC} 2$ was found not to affect the bulk fluidity. The fluidity of vesicles, which do not contain $\mathrm{CC} 2$, was not affected by WGA either at the surface or in the bulk. It is concluded that the present system reproduces well some cell phenomena such as the mitogen-induced phase separation of cell membrane $^{20}$ and constitutes a basis for the development of biocompatible synthetic materials.

\section{REFERENCES}

1. Yu. A. Ovchinnikov and V. T. Ivanov, Tetrahedron, 31, 2177 (1975).

2. S. Kimura and Y. Imanishi, Biopolymers, 22, 2191 (1983).

3. S. Kimura and Y. Imanishi, Biopolymers, 22, 2383 (1983).

4. S. Kimura and Y. Imanishi, Biopolymers, 23, 563 (1984).
5. D. W. Urry, Proc. Natl. Acad. Sci. U.S.A., 69, 1610 (1972).

6. M. Tomita, H. Furthmayr, and V. T. Marchesi, Biochemistry, 17, 4756 (1978).

7. N. V. Ketis and C. W. M. Grant, Biochim. Biophys. Acta, 685, 374 (1982).

8. F. Jordan, H. Bahr, J. Patrick, and P. W. K. Woo, Arch. Biochem. Biophys., 207, 81 (1981).

9. R. Ashton and L. K. Steinrauf, J. Mol. Biol., 49, 547 (1970).

10. M. K. Mathew, R. Nagaraj, and P. Balaram, $J$. Membrane Biol., 65, 13 (1982).

11. F. Szoka, Jr. and D. Papahadjopoulos, Proc. Natl. Acad. Sci. U.S.A., 75, 4194 (1978).

12. M. Shinitzky and Y. Barenholz, J. Biol. Chem., 249, 2652 (1974).

13. M. Kondo, I. Nishi, K. Okamoto, T. Kato, and N. Izumiya, "Peptides," Proc. 7th American Peptide Symposium, 1981, pp 291-294.

14. J. D. Lamb, J. J. Christensen, J. L. Oscarson, B. L. Nielsen, B. W. Asay, and R. M. Izatt, J. Am. Chem. Soc., 102, 6820 (1980).

15. R. Nagaraj and P. Balaram, Biochemistry, 20, 1610 (1972).

16. E. Benedetti, A. Bavoso, B. Di Blasio, V. Pavone, C. Pedone, M. Crisma, C. M. Bnora, and C. Toniolo, J. Am. Chem. Soc., 104, 2437 (1982).

17. Y. V. Venkatachalapathi, P. Balaram, Biopolymers, 20, 1137 (1981).

18. G. Boheim, J. Membrane Biol., 19, 277 (1974).

19. A. Uemura, S. Kimura, and Y. Imanishi, Biochim. Biophys. Acta, 729, 28 (1983).

20. R. D. Vale and E. M. Shooter, J. Cell Biol., 94, 710 (1982). 